\title{
Editorial
}

\section{A CHANGE}

With this issue of The Journal, new hands take the helm [Editor Edward B. Shuttleworth resigned and J.E. Morrison took over]. The hand which launched it upon the seas of journalism at a time when pharmacy had no legal standing in Canada, and which has since steered it through calms and hurricanes some of which would have wrecked vessels less strongly built, now resigns his charge to other hands. During the thirty years of its existence The Canadian Pharmaceutical Journal has assisted at the birth of the many pharmaceutical associations of this country, and has seen them grow from puny weaklings, struggling with many foes, to the lusty powerful organizations of today, and we will be pardoned if we say that the growth and strength of our associations are in a great measure due to the strenuous battle fought by this journal to secure recognition of the rights of the pharmacist. When pharmacy was in a state of chaos, when we might say pharmacy as such had no existence in this country, when our associations were still in the womb of the future, this journal was founded for the purpose of fostering pharmacal education and organization, and we have succeeded in our efforts. Today our provincial associations are second to none, and the condition of pharmacy in Canada compares favorably with that obtaining in any other part of America.

The policy mapped out and followed by its founder will still be ours; the interests of the retail pharmacist will be our interests, and his battles our battles, and whenever needed our pen and talents will always be at his service in the fight against quackery and illegal competition. We will not bind ourselves to any organization, but will remain free to help in any way we see judicious. If by praise the actions of any association can be aided, then we will praise, but if criticism be necessary, we will criticise. None of us can be perfect, and no two men see eye to eye, and frequently criticism will do good where fulsome flattery would tend to perpetuate errors or wrong lines of conduct, which would lead to injury; then we will exercise our right of criticism.

Any and all means to benefit the pharmacist will have our active co-operation. We know that many so-called pharmaceutical journals have through their subserviency to certain interests, formerly noted for their hostility to the pharmacist, fostered the idea that all journals were in the same boat, but in that respect the independence which has always characterized this journal will be retained.

No effort will be spared by us to make the Canadian Pharmaceutical Journal typical of what is best in Canadian Pharmacy, but our unaided efforts will not avail; we want the help of every pharmacist in this country in the work of keeping the Ganadian Pharmaceutical Journal at the head of the procession. We want Canadian pharmacists to be a little less bashful in that they should use their pens to a greater extent, and let the world know of their discoveries and inventions by writing us short accounts of improvements which they have made in existing processes, or new methods of manipulation or manufacture, all of which would prove interesting to your brother pharmacists.

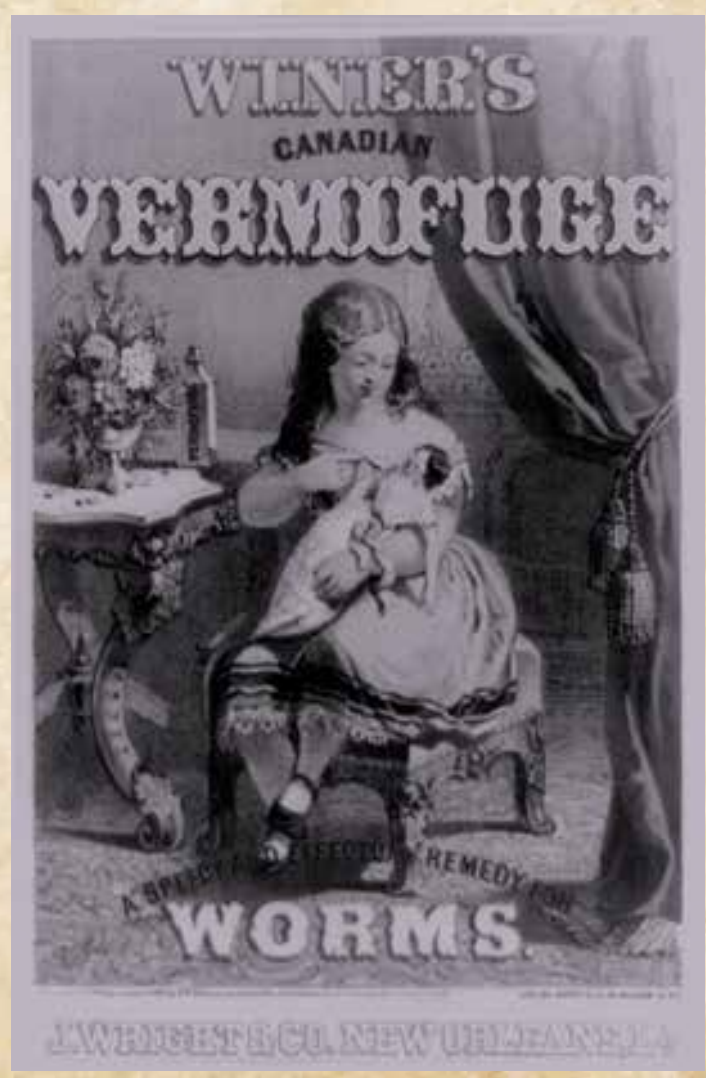




\section{WILLIAM R. WARNER \& CO. (FOOXDDD 1856)}

THE * LARGEST * PILL * MANUFACTORY * IN * THE * WORLD

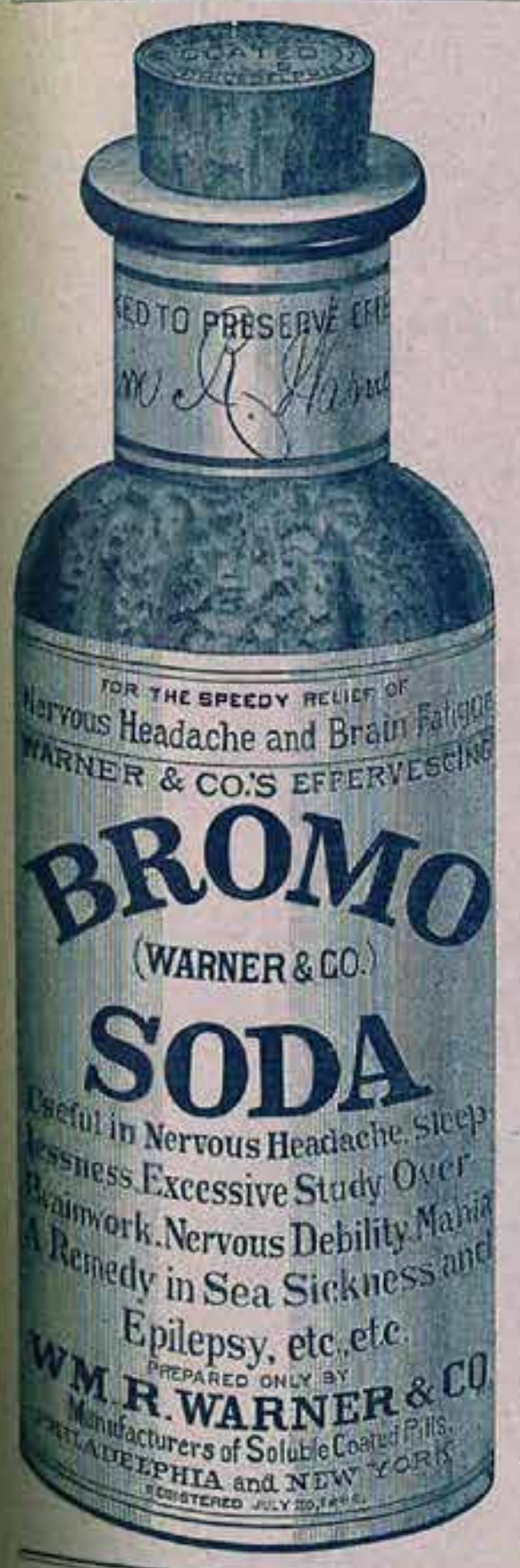

\section{Little Cathartic Granules}

There is Nothing Superior for a Little Liver Pill

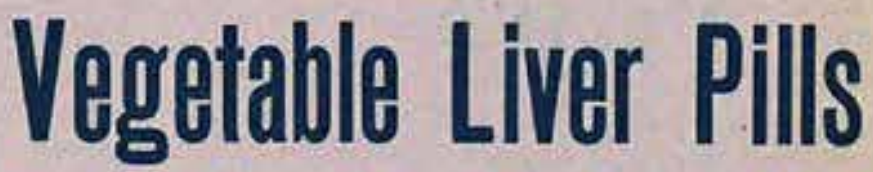

An Elegant Pill as a Laxative or Cathartic According to the Dose

Send an Order for Either of the Above Pills Put Up in Elegant Style with Your Name and Address on.

CORRESPONDENCE SOLYTTED

Compressed Soda Mint ${ }^{\text {in }} \begin{gathered}\text { Oral bothes with nickiled screw cap, each } \\ \text { dozen in }\end{gathered}$ Compressed Chlorate Potash Tablets.

Compressed Brown Mixture Tablets.

Compressed Paregoric Tablets.

Cathartic Comp. U. S.P.

Cathartic Comp. U. S. P., Gelatin Coated.

Cathartic Comp. Active.

Aromatic Cachous. . Coated with Pure Sugar.

Aromatic Cachous. In Oval botstes with nickited screw capa.

WM. R. WARNER \& CO., Manufacturing Chemists 1228 Market Street, PHLLoelphia 